\title{
Pediatric hydrocephalus: systematic literature review and evidence-based guidelines. Part 4: Cerebrospinal fluid shunt or endoscopic third ventriculostomy for the treatment of hydrocephalus in children
}

\author{
David D. Limbrick JR., M.D., Ph.D., ${ }^{1}$ Lissa C. Baird, M.D., ${ }^{2}$ \\ Paul Klimo Jr., M.D., M.P.H., ${ }^{3-5}$ JaY Riva-Cambrin, M.D., M.Sc., $^{6}$ \\ And Ann Marie Flannery, M.D. ${ }^{7}$ \\ ${ }^{1}$ Division of Pediatric Neurosurgery, Department of Neurological Surgery, Washington University School of \\ Medicine, St. Louis, Missouri; ${ }^{2}$ Department of Neurological Surgery, Oregon Health \& Science University, \\ Portland, Oregon; ${ }^{3}$ Semmes-Murphey Neurologic \& Spine Institute, ${ }^{4}$ Department of Neurosurgery, University \\ of Tennessee Health Science Center, and ${ }^{5}$ Le Bonheur Children's Hospital, Memphis, Tennessee; ${ }^{\circ}$ Division \\ of Pediatric Neurosurgery, University of Utah School of Medicine, Salt Lake City, Utah; ${ }^{7}$ Department of \\ Neurological Surgery, Saint Louis University, St. Louis, Missouri
}

\begin{abstract}
Object. The objective of this systematic review was to examine the existing literature comparing CSF shunts and endoscopic third ventriculostomy (ETV) for the treatment of pediatric hydrocephalus and to make evidence-based recommendations regarding the selection of surgical technique for this condition.

Methods. Both the US National Library of Medicine and the Cochrane Database of Systematic Reviews were queried using MeSH headings and key words specifically chosen to identify published articles detailing the use of CSF shunts and ETV for the treatment of pediatric hydrocephalus. Articles meeting specific criteria that had been determined a priori were examined, and data were abstracted and compiled in evidentiary tables. These data were then analyzed by the Pediatric Hydrocephalus Systematic Review and Evidence-Based Guidelines Task Force to consider treatment recommendations based on the evidence.

Results. Of the 122 articles identified using optimized search parameters, 52 were recalled for full-text review. One additional article, originally not retrieved in the search, was also reviewed. Fourteen articles met all study criteria and contained comparative data on CSF shunts and ETV. In total, 6 articles (1 Class II and 5 Class III) were accepted for inclusion in the evidentiary table; 8 articles were excluded for various reasons. The tabulated evidence supported the evaluation of CSF shunts versus ETV. studied.

Conclusions. Cerebrospinal fluid shunts and ETV demonstrated equivalent outcomes in the clinical etiologies

RECOMMENDATION: Both CSF shunts and ETV are options in the treatment of pediatric hydrocephalus. STRENGTH OF RECOMMENDATION: Level II, moderate clinical certainty. (http://thejns.org/doi/abs/10.3171/2014.7.PEDS14324)
\end{abstract}

KEY WORDS
shunt $\bullet$ hydrocephalus $\bullet \quad$ cerebrospinal fluid $\bullet$ ventriculoperitoneal

$\mathrm{S}$ ELECTION of the appropriate surgical method-CSF shunt placement or endoscopic third ventriculostomy (ETV) - for the treatment of pediatric hydrocephalus remains a topic of considerable debate. Advocates for ETV cite low failure rates and the potential to avoid shunt placement and its inherent risks as major advantages of the procedure, while supporters of inser-

\footnotetext{
Abbreviations used in this paper: AANS $=$ American Association of Neurological Surgeons; CNS = Congress of Neurological Surgeons; $\mathrm{CPC}=$ choroid plexus cauterization; $\mathrm{ETV}=$ endoscopic third ventriculostomy; $\mathrm{VP}=$ ventriculoperitoneal.
}

tion of a ventriculoperitoneal (VP) shunt question the efficacy of ETV in treating hydrocephalus as well as ETV's unknown effects on neurodevelopment and quality of life..$^{2,4,11}$ While there is a great deal of literature on CSF shunts and ETV, there is a relative dearth of articles describing evaluation of both CSF shunt placement and ETV, and there are no randomized trials in which the 2 procedures have been compared.

Endoscopic third ventriculostomy may be beneficial in cases in which there is a clear obstruction to CSF flow and ETV provides an alternate pathway. It is less certain that ETV holds an advantage over shunts in many other 


\section{Part 4: CSF shunt placement versus ETV for treating hydrocephalus}

causes of hydrocephalus. There is a great deal of interest in the use of ETV with choroid plexus coagulation (CPC) in the treatment of infant hydrocephalus. The Pediatric Hydrocephalus Systematic Review and Evidence-Based Guidelines Task Force anticipates that this topic, along with the effectiveness of ETV compared with shunts in treating hydrocephalus of specific etiologies, will be addressed in subsequent publications. In the current analysis, we sought to systematically review the existing literature detailing the efficacy of CSF shunts versus ETV and to generate evidence-based recommendations for the selection of surgical procedure based on the strength of the available data. Evidence for ETV and a discussion of that procedure in infants younger than 1 year of age is addressed elsewhere in the Guidelines. ${ }^{14}$

The primary objective of this work was to broadly assess treatment outcomes and review evidence that one treatment may have greater efficacy than the other.

\section{Methods}

\section{Search Criteria}

The US National Library of Medicine PubMed/ MEDLINE database and the Cochrane Database of Systematic Reviews were queried using MeSH headings, key words, and terms relevant to hydrocephalus, CSF shunts, and ETV. The structure of the literature queries used to search these databases for published articles relevant to hydrocephalus, CSF shunts, and ETV is explained below and in "Part 1: Introduction and Methods."

\section{Search Terms}

\section{PubMed/MEDLINE}

1. (("Hydrocephalus"[Majr]) AND "Ventriculostomy"[Majr]) AND “Endoscopy”[Mesh]

2. Limit 1 to Child (0-18 years)

3. Limit to English and Humans

Number $=120$

Cochrane Database

1. MeSH descriptor Child

2. MeSH descriptor Infant

3. MeSH descriptor Hydrocephalus

4. MeSH descriptor Ventriculostomy

5. MeSH descriptor Third Ventricle

6. (1 or 2$)$ and 3 and 4

7. (1 or 2$)$ and 3 and 5

Number $=2$ Systematic Reviews

Abstracts of papers that were identified using these optimized search parameters $(n=122)$ were screened for inclusion criteria. Electronic searches were supplemented by manual searches of article bibliographies. Of the 122 records that were screened, 52 articles were recalled for a full-text review. One additional article identified but not retrieved in the search was also reviewed. Fourteen articles contained comparative data on CSF shunts and ETV, a criterion defined a priori for the current study. Please refer to Part 1 of the Guidelines, ${ }^{7}$ which offers additional inclusion/exclusion criteria and search terms that were used.

\section{Search Strategy}

An evidentiary table was constructed to facilitate data review and analysis by the Task Force. Each of the 14 articles was read and reviewed in detail by the full Task Force. Afterward 7 articles were excluded due to potential redundancy in the subject population $(n=3)$, potential redundancy and variable or inappropriate outcome measures $(n=2)$, or a clinical scenario in which hydrocephalus might reasonably be expected to resolve without ETV or shunt surgery $(\mathrm{n}=2)$; and 1 article was excluded because it covered simultaneous treatment with a CSF shunt and ETV (Fig. 1). ${ }^{5,6,10-12,15,16,19}$ The evidentiary table was constructed to link recommendations to strengths of evidence (Levels I-III), which were assigned by a group consensus during face-to-face meetings of the Task Force.

\section{Search Results}

Of the 122 articles identified using the optimized search parameters, 52 were recalled for full-text review. Members of the Task Force who were assigned to the current topic read and discussed all 52 articles recalled for the full-text review as well as the additional study identified and subsequently disqualified. As the primary objective of this study was to assess treatment outcomes following placement of a CSF shunt or ETV, the scope of the evidentiary review was limited to studies that reported quantitative outcomes on both procedures $(n=14)$. In total, 6 articles (1 Class II and 5 Class III) were accepted for inclusion in the evidentiary table (Table 1$)^{1,3,8,9,17,18}$ and 8 were excluded for various reasons as detailed above. . $^{5,6,10-12,15,16,19}$ When more than 1 paper covered the same clinical material or included the same subjects, only the paper with the largest patient population and most current data was included in the evidentiary table. The tabulated evidence provided adequate data to allow our evaluation of CSF shunts versus ETV.

Two articles ${ }^{5,10}$ were excluded because they contained redundant material or constituted duplicate publication. When more than 1 paper covered the same clinical material, only the paper with the largest patient population and most current data was included in Table 1 as evidence to support the topic. Two other articles by the same group of researchers were also excluded: one because of possible subject redundancy and insufficient data to address the primary objective, ${ }^{11}$ and the other because it contained differing outcome measures. ${ }^{12}$ Two articles were excluded because they evaluated the role of $\mathrm{ETV}^{15}$ or ETV and CSF shunts ${ }^{6}$ prior to posterior fossa surgery for tumor excision, a clinical scenario in which hydrocephalus may reasonably be expected to resolve in some cases. Finally, 1 article was excluded because its topic was simultaneous ETV and CSF shunt implantation, which prohibited an assessment of the outcome of either procedure alone. ${ }^{16}$

\section{Results}

ReCOMMENDATION: Both CSF shunts and ETV are options in the treatment of pediatric hydrocephalus. StRENGTH of Recommendation: Level II, moderate clinical certainty. 


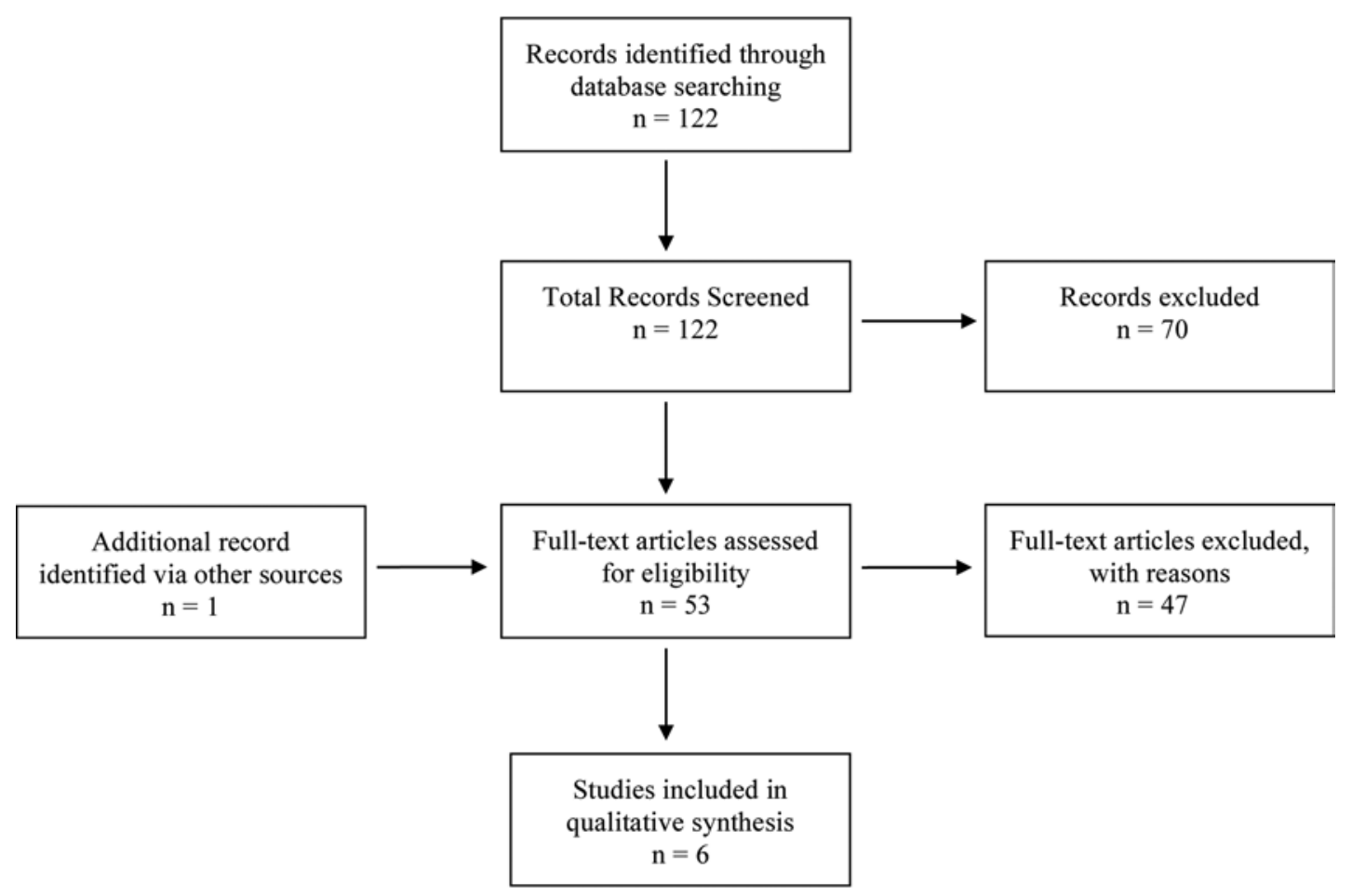

FIG. 1. Flowchart showing the process involved in identifying relevant literature. See text for exclusion criteria at each stage.

Cerebrospinal fluid shunts and ETV demonstrated equivalent outcomes in the clinical scenarios that were studied.

All relevant articles, including those planned for inclusion and exclusion, were reviewed before finalizing the evidentiary table. Each article was presented and discussed in detail, and careful deliberation was made to determine each article's data class. In sum, there were 5 Class III articles and 1 Class II article (Table 1).

Tuli et al. (1999) published the sole article included in the evidentiary table rated as Class II. ${ }^{18}$ The authors reported results from a single-center, nonrandomized, prospective cohort study investigating outcomes in 242 consecutive patients treated with ETV $(\mathrm{n}=32)$ or VP shunts ( $=210$ ). While differences in patient ages and the etiology of hydrocephalus were noted among groups (patients who underwent ETV were older at surgery and more likely to have aqueductal stenosis), no significant difference was observed in the procedure failure rate, with a $44 \%$ failure rate for ETV and a 45\% failure rate for VP shunt surgery.

The remaining 5 articles included in the evidentiary table were rated as Class III studies. Appelgren and colleagues $^{1}$ (2010) reported a retrospective analysis of prospectively acquired data in 98 patients treated with VP shunts (76 patients) or ETV (22 patients). The primary outcome was failure of the surgery, which was recorded when subsequent surgery was required. Failure rates for VP shunt surgery and ETV were 58\% and 55\%, respectively, with a mean follow-up of 4.7 years. Study group allocation was uncontrolled, and there was variability in patient ages at surgery, the etiology of hydrocephalus, and other factors.

De Ribaupierre et al. ${ }^{3}$ (2007) reported the results of a retrospective review of 55 procedures (24 ETVs and
$31 \mathrm{VP}$ shunt placements) performed in 48 patients in the context of a literature review. With a median follow-up of 39 months, the authors noted a trend toward a lower failure rate in the ETV group (26\% vs $42 \%$ in the VP shunt group), although this was not significant. The authors acknowledged nonsignificant differences in patient age and sex as well as in the etiology of hydrocephalus among their groups. Shimizu et al. ${ }^{17}(2012)$ presented a retrospective, 2-center review of cases in which ETV (9 patients) or VP shunt surgery (36 patients) was performed after removal of infected shunts. No significant difference was observed between the 2 groups in reinfection rates or procedural longevity. Of note, however, 7 of the 9 ETVs ultimately failed in this case series of patients being treated after shunt infection.

Garton et al. ${ }^{8}$ (2002) reported a retrospective, singleinstitution, matched cohort study in which ETV was compared with VP shunt surgery. With 28 patients in each group, no significant differences were noted between the 2 procedures in the treatment success rate or in cost-effectiveness parameters such as length of stay, operating time, or cost per patient. The authors acknowledge several limitations in this study, including modest sample sizes, a long treatment interval with practice deviation over time, and the possibility of missing late ETV failures (there was 1 hydrocephalus-related death in this group).

The largest study included in the evidentiary table was conducted by Kulkarni et al. ${ }^{9}$ (2010). This large multicenter comparative study had 2 arms: a retrospective arm for ETV $(\mathrm{n}=489)$, and an arm in which prospectively acquired data for VP shunts was obtained from 2 previous clinical trials and reanalyzed for this study $(\mathrm{n}=$ 720). As noted previously, several related studies by the 
Part 4: CSF shunt placement versus ETV for treating hydrocephalus

TABLE 1: Evaluation of CSF shunt procedures and ETV: summary of evidence*

\begin{tabular}{|c|c|c|c|}
\hline Authors \& Year & Study Description & Data Class, Quality, \& Reasons & Results \& Conclusions \\
\hline Tuli et al., 1999 & $\begin{array}{l}\text { Single-center, nonrandomized, prospec- } \\
\text { tive cohort study. } \\
\text { Analysis of all pts w/ hydrocephalus from } \\
\text { aqueductal stenosis or tumor over a } \\
\text { 10-yr period. }\end{array}$ & $\begin{array}{l}\text { Class II } \\
\text { Prospective cohort study of consecu- } \\
\quad \text { tive pts. }\end{array}$ & $\begin{array}{l}\text { ETV: } 32 \text { pts, } 14 \text { procedure failures ( } 44 \% \text { ); VP } \\
\text { shunt surgery: } 210 \text { pts, } 95 \text { procedure failures } \\
(45 \%) \text {. } \\
\text { ETV group had older pts (median age }=8.1 \text { vs } \\
3.6 \text { yrs) \& had higher incidence of aqueduc- } \\
\text { tal stenosis ( } 53 \% \text { vs } 25 \% \text { ). No difference } \\
\text { observed btwn groups ( } p=0.66, \text { HR } 1.19 \\
95 \% \mathrm{Cl} 0.55-2.56 \text { ). }\end{array}$ \\
\hline $\begin{array}{l}\text { Appelgren et } \\
\text { al., } 2010\end{array}$ & $\begin{array}{l}\text { Retrospective analysis of a prospective } \\
\text { case series of } 98 \text { pts treated w/ a VP } \\
\text { shunt or ETV. Primary outcome: proce- } \\
\text { dure failure for a VP shunt or ETV. Time } \\
\text { to failure also recorded. }\end{array}$ & $\begin{array}{l}\text { Class III } \\
\text { Retrospective analysis of an uncon- } \\
\quad \text { trolled, prospective case series. }\end{array}$ & $\begin{array}{l}\text { Failure rates: ETV group 55\%, VP shunt group } \\
58 \% \text {. } \\
\text { Hazard ratios calculated for failure of shunts, pt } \\
\text { prematurity, \& length of procedure. Variabil- } \\
\text { ity present in pt age, etiology of hydrocepha- } \\
\text { lus, \& other factors. }\end{array}$ \\
\hline $\begin{array}{l}\text { De Ribaupierre } \\
\text { et al., } 2007\end{array}$ & $\begin{array}{l}\text { Retrospective review of } 55 \text { procedures in } \\
48 \text { consecutive pts (ETV: } 24 \text { pts; VP } \\
\text { shunt surgery: } 31 \text { pts). }\end{array}$ & $\begin{array}{l}\text { Class III } \\
\text { Retrospective review. }\end{array}$ & $\begin{array}{l}\text { Difference in failure rate not significant ( } 26 \% \text { w/ } \\
\text { ETV vs } 42 \% \text { w/ VP shunt surgery). } \\
\text { No difference btwn groups at } 6 \text { mos, } 1 \text { yr, } 2 \text { yrs, } \\
\text { or } 5 \text { yrs after surgery. }\end{array}$ \\
\hline $\begin{array}{l}\text { Garton et al., } \\
2002\end{array}$ & $\begin{array}{l}\text { Matched cohort analysis of ETV vs VP } \\
\text { shunt w/ comparison of cost-effective- } \\
\text { ness \& procedure failure rate. } \\
28 \text { pts in each group. }\end{array}$ & $\begin{array}{l}\text { Class III } \\
\text { Retrospective single-institution } \\
\text { matched cohort study. Study } \\
\text { interval was prolonged (10 yrs) \& } \\
\text { contained practice variation. }\end{array}$ & $\begin{array}{l}\text { ETV success rate of } 54 \% \text { was not significantly } \\
\text { different from that of VP shunt surgery. } \\
\text { However, at } 34 \text { mos postop, the procedure } \\
\text { survival curve favored ETV. No difference } \\
\text { btwn procedures observed in cost or ef- } \\
\text { ficacy. }\end{array}$ \\
\hline $\begin{array}{l}\text { Kulkarni et al., } \\
2010^{9}\end{array}$ & $\begin{array}{l}\text { International multicenter study comparing } \\
\text { retrospective data for ETV \& prospec- } \\
\text { tively acquired data for shunts (from the } \\
\text { Shunt Design Trial \& the Endoscopic } \\
\text { Shunt Insertion Trial). Primary outcome: } \\
\text { treatment failure (requirement for } \\
\text { subsequent hydrocephalus surgery or } \\
\text { hydrocephalus-related death). }\end{array}$ & $\begin{array}{l}\text { Class III } \\
\text { Multicenter comparative study w/ } 2 \\
\text { arms: } 1 \text { ) retrospective for ETV; } 2 \text { ) } \\
\text { prospectively acquired data from } \\
2 \text { previous trials re-analyzed in the } \\
\text { current study. }\end{array}$ & $\begin{array}{l}\text { Unadjusted models showed lower rates of } \\
\text { failure for ETV than for shunting. After } \\
\text { adjusting for age \& hydrocephalus etiology, } \\
\text { ETV had a higher early rate of failure than } \\
\text { shunting. However, the ETV failure rate was } \\
\text { lower than that for shunting at points after } 3 \\
\text { mos postsurgery. }\end{array}$ \\
\hline $\begin{array}{l}\text { Shimizu et al., } \\
2012\end{array}$ & $\begin{array}{l}\text { Retrospective 2-center study of ETV }(n= \\
\text { 9) \& VP shunt }(n=36) \text { after removal of } \\
\text { infected VP shunt. Compared reinfec- } \\
\text { tion rates after each procedure \& } \\
\text { procedure survival. }\end{array}$ & $\begin{array}{l}\text { Class III } \\
\text { Retrospective review, modest sample } \\
\quad \text { size. }\end{array}$ & $\begin{array}{l}\text { Reinfection rates were not significantly differ- } \\
\text { ent btwn VP shunt }(27.8 \%) \text { \& ETV (11.1\%) } \\
\text { groups. Procedure survival was not signifi- } \\
\text { cantly different btwn VP shunt (658 days) \& } \\
\text { ETV (929 days). }\end{array}$ \\
\hline
\end{tabular}

${ }^{*}$ pts $=$ patients.

same research group were excluded, because there was likely overlap in the patients included in these studies. Although this paper was rated by the Task Force as Class III, Kulkarni et al. described a sophisticated analysis of ETV versus VP shunt surgery on a large scale. The initial unadjusted models showed lower rates of failure for ETV compared with shunt surgery, but when adjusted for patient age and hydrocephalus etiology, the comparison became more complicated: early failure was higher for ETV than for shunt placement, but at points after 3 months, the ETV failure rate was lower than that for shunt surgery. Based on these findings, the authors concluded that there may be a long-term treatment survival advantage for ETV.

Ultimately, there are a number of limitations to this systematic review. In narrowing the scope of this project to focus specifically on evaluating the method of hydrocephalus treatment-VP shunt or ETV—-several key factors known to impact the success of ETV, namely patient age, etiology of hydrocephalus, and history of prior hydrocephalus surgery, were not assessed..$^{10}$ Thus, the heterogeneity in subject data that we have analyzed herein inherently limits the ability of this recommendation to inform surgical decision making in any specific case. Further, emerging information regarding the role of choroid plexus cauterization (CPC) in conjunction with ETV and alternative indications for ETV with or without CPC (for example, posthemorrhagic hydrocephalus of prematurity) should be evaluated in future iterations of guidelines for the treatment of hydrocephalus as more information becomes available. ${ }^{19}$ Finally, and most significantly, there is an urgent need for largescale randomized controlled trials to generate the Level I evidence that is required to definitively address the question of the optimal surgical technique (VP shunt, ETV, or ETV-CPC) in cases of any given hydrocephalus etiology. 


\section{Conclusions}

ReCommendation: Both CSF shunts and endoscopic third ventriculostomy (ETV) are options in the treatment of pediatric hydrocephalus. STRENGTH OF RECOMMENDATION: Level II, moderate clinical certainty.

Cerebrospinal fluid shunts and ETV demonstrated equivalent outcomes in the clinical scenarios that were studied.

\section{Acknowledgments}

We acknowledge the American Association of Neurological Surgeons (AANS)/Congress of Neurological Surgeons (CNS) Joint Guidelines Committee for the members' reviews, comments, and suggestions; Laura Mitchell, Guidelines Project Manager for the CNS, for her contributions; Pamela Shaw, research librarian, for her assistance with the literature searches; Kevin Boyer for his assistance with data analysis; and Sue Ann Kawecki for her assistance with editing.

\section{Disclosure}

Dr. Limbrick receives research funding through the National Institute of Neurological Disorders and Stroke. The systematic review and evidence-based guidelines were funded exclusively by the CNS and AANS Pediatric Section, which received no funding from outside commercial sources to support the development of this document.

Conflict(s) of Interest: None. All Task Force members declared any potential conflicts of interest prior to beginning work on this evidence review.

Author contributions to the study and manuscript preparation include the following. Conception and design: AANS/CNS Joint Section on Pediatrics. Acquisition of data: all authors. Analysis and interpretation of data: all authors. Drafting the article: Limbrick. Critically revising the article: all authors. Reviewed submitted version of manuscript: all authors. Approved the final version of the manuscript on behalf of all authors: Flannery. Administrative/technical/ material support: all authors. Study supervision: Flannery.

\section{References}

1. Appelgren T, Zetterstrand S, Elfversson J, Nilsson D: Longterm outcome after treatment of hydrocephalus in children. Pediatr Neurosurg 46:221-226, 2010

2. Buckley RT, Yuan W, Mangano FT, Phillips JM, Powell S, McKinstry RC, et al: Longitudinal comparison of diffusion tensor imaging parameters and neuropsychological measures following endoscopic third ventriculostomy for hydrocephalus. Case report. J Neurosurg Pediatr 9:630-635, 2012

3. de Ribaupierre S, Rilliet B, Vernet O, Regli L, Villemure JG: Third ventriculostomy vs ventriculoperitoneal shunt in pediatric obstructive hydrocephalus: results from a Swiss series and literature review. Childs Nerv Syst 23:527-533, 2007

4. Di Rocco C, Massimi L, Tamburrini G: Shunts vs endoscopic third ventriculostomy in infants: are there different types and/or rates of complications? A review. Childs Nerv Syst 22:1573-1589, 2006

5. Drake JM, Kulkarni AV, Kestle J: Endoscopic third ventriculostomy versus ventriculoperitoneal shunt in pediatric patients: a decision analysis. Childs Nerv Syst 25:467-472, 2009

6. El-Ghandour NMF: Endoscopic third ventriculostomy versus ventriculoperitoneal shunt in the treatment of obstructive hydrocephalus due to posterior fossa tumors in children. Childs Nerv Syst 27:117-126, 2011
7. Flannery AM, Mitchell L: Pediatric hydrocephalus: systematic literature review and evidence-based guidelines. Part 1: Introduction and methodology. J Neurosurg Pediatr 14 (Suppl):3-7, 2014

8. Garton HJ, Kestle JR, Cochrane DD, Steinbok P: A cost-effectiveness analysis of endoscopic third ventriculostomy. Neurosurgery 51:69-78, 2002

9. Kulkarni AV, Drake JM, Kestle JR, Mallucci CL, Sgouros S, Constantini S: Endoscopic third ventriculostomy vs cerebrospinal fluid shunt in the treatment of hydrocephalus in children: a propensity score-adjusted analysis. Neurosurgery 67:588-593, 2010

10. Kulkarni AV, Drake JM, Kestle JR, Mallucci CL, Sgouros S, Constantini S: Predicting who will benefit from endoscopic third ventriculostomy compared with shunt insertion in childhood hydrocephalus using the ETV Success Score. Clinical article. J Neurosurg Pediatr 6:310-315, 2010 (Erratum in J Neurosurg Pediatr 7:221, 2011)

11. Kulkarni AV, Shams I, Cochrane DD, McNeely PD: Does treatment with endoscopic third ventriculostomy result in less concern among parents of children with hydrocephalus? Childs Nerv Syst 26:1529-1534, 2010

12. Kulkarni AV, Shams I, Cochrane DD, McNeely PD: Quality of life after endoscopic third ventriculostomy and cerebrospinal fluid shunting: an adjusted multivariable analysis in a large cohort. Clinical article. J Neurosurg Pediatr 6:11-16, 2010

13. Kulkarni AV, Warf BC, Drake JM, Mallucci CL, Sgouros S, Constantini S: Surgery for hydrocephalus in sub-Saharan Africa versus developed nations: a risk-adjusted comparison of outcome. Childs Nerv Syst 26:1711-1717, 2010

14. Mazzola CA, Choudhri AF, Auguste KI, Limbrick DD Jr., Rogido M, Mitchell L, et al: Pediatric hydrocephalus: systematic literature review and evidence-based guidelines. Part 2: Management of posthemorrhagic hydrocephalus in premature infants. J Neurosurg Pediatr 14 (Suppl):8-23, 2014

15. Sainte-Rose C, Cinalli G, Roux FE, Maixner R, Chumas PD, Mansour M, et al: Management of hydrocephalus in pediatric patients with posterior fossa tumors: the role of endoscopic third ventriculostomy. J Neurosurg 95:791-797, 2001

16. Shim KW, Kim DS, Choi JU: Simultaneous endoscopic third ventriculostomy and ventriculoperitoneal shunt for infantile hydrocephalus. Childs Nerv Syst 24:443-451, 2008

17. Shimizu T, Luciano MG, Fukuhara T: Role of endoscopic third ventriculostomy at infected cerebrospinal fluid shunt removal. Clinical article. J Neurosurg Pediatr 9:320-326, 2012

18. Tuli S, O'Hayon B, Drake J, Clarke M, Kestle J: Change in ventricular size and effect of ventricular catheter placement in pediatric patients with shunted hydrocephalus. Neurosurgery 45:1329-1335, 1999

19. Warf BC, Campbell JW, Riddle E: Initial experience with combined endoscopic third ventriculostomy and choroid plexus cauterization for post-hemorrhagic hydrocephalus of prematurity: the importance of prepontine cistern status and the predictive value of FIESTA MRI imaging. Childs Nerv Syst 27:1063-1071, 2011

Manuscript submitted June 25, 2014.

Accepted July 7, 2014.

Please include this information when citing this paper: DOI: 10.3171/2014.7.PEDS14324.

Address correspondence to: Ann Marie Flannery, M.D., Department of Neurological Surgery, Saint Louis University, 3565 Vista Ave., St. Louis, MO 63110. email: flanneam@slu.edu. 